\title{
Severely ectatic left circumflex coronary artery with fistula to coronary sinus presenting with acute coronary syndrome
}

\author{
Ahmed Sayed
}

\begin{abstract}
Introduction: Coronary artery fistulas are uncommon anomalies. They occur in $0.1-0.8 \%$ of patients undergoing coronary arteriography. The circumflex coronary arteriovenous fistulae (CAF) associated with aneurysmal dilatation and drainage into coronary sinus (CS) are even less common. We present a case of a 56-yearold male with an acute coronary syndrome who was found to have a tortuous and aneurysmal circumflex coronary artery terminating into the CS. Case report: A previously healthy 56-yearold male developed acute retrosternal chest pain while skiing. Physical examination revealed a grade II/VI continuous murmur at the left lower sternal border, but was otherwise unremarkable. Laboratory investigations revealed an elevated troponin and ST depression in the inferior leads on his electrocardiography. Coronary angiography showed a diffusely aneurysmal circumflex artery with a fistula to the CS. The patient underwent successful surgical ligation of the fistula. Conclusion: Our patient presented with an acute coronary syndrome caused by an uncommon form of coronary artery fistula. Conventional coronary angiography failed to fully define the anatomy of the fistula (origin, pathway, and outflow). Multidetector computed tomography was complementary to demonstrate the complex anatomy of the fistula. The fistula was surgically ligated and he remains well.
\end{abstract}

Ahmed Sayed

Affiliations: MD, Department of Cardiology, University of Calgary, Calgary, Canada.

Corresponding Author: Ahmed Sayed, MD, Department of Cardiology, University of Calgary, Calgary, Canada; Email: sayed326@yahoo.com

Received: 05 July 2013

Accepted: 05 August 2013

Published: 01 December 2013
Keywords: Coronary artery fistula, Coronary artery angiogram, Acute coronary syndrome

$* * * * * * * * *$

Sayed A. Severely ectatic left circumflex coronary artery with fistula to coronary sinus presenting with acute coronary syndrome. International Journal of Case Reports and Images 2013;4(12):727-730.

$* * * * * * * * *$

doi:10.5348/ijcri-2013-12-421-CR-15

\section{INTRODUCTION}

An aneurysmal left circumflex coronary artery (LCX) with associated fistulous connection to the coronary sinus (CS) is an extremely uncommon coronary artery anomaly. A few patients have been reported in literature. The majority of these cases were asymptomatic and presented late in life. Accurate diagnosis of these fistulas often requires multiple imaging modalities to delineate the entire pathway of the fistula. Multiple treatment options are available including surgery, trans catheter closure, and conservative management.

\section{CASE REPORT}

A 56-year-old male, who was on a skiing trip, was presented with sudden onset of retrosternal chest pressure with shortness of breath and diaphoresis. There was no family history of congenital heart disease or other inherited abnormalities. Physical Examination revealed normal vital signs and a grade II continuous murmur loudest at the left sternal border in the fourth intercostal space. The electrocardiography showed inferior ST segment depression and his high sensitivity troponin- $\mathrm{T}$ was $417 \mathrm{ng} / \mathrm{L}$. A posteroanterior and lateral X-ray of chest showed only mild cardiomegaly. 
Transthoracic echocardiography (TTE) showed a dilated structure in the atrioventricular groove and there was mild hypokinesis of the basal inferior and inferolateral walls of the left ventricle. The right atrium was mildly enlarged. Coronary angiography revealed a tortuous and ectatic left circumflex artery with a large arteriovenous fistula draining into the CS without evidence of atherosclerothic narrowing of the coronary arteries (Figure 1). The computed tomography (CT) angiography confirmed the fistula between circumflex artery and the CS (Figure 2A, B). The patient was initially treated as an acute coronary syndrome with ASA, Plavix, enoxaparin in addition to an ACEi and a statin. Following diagnosis of the congenital coronary fistula, he underwent successful surgical ligation. He was subsequently discharged home on ASA, a statin and an ACEi.

\section{DISCUSSION}

Coronary arteriovenous fistulas (CAFs) are considered a major coronary anomaly [1], with an incidence of $0.1 \%$ to $0.87 \%[2,3]$. The majority of cases originate from the right coronary and left anterior descending coronary arteries. Coronary artery fistulas originating from the circumflex coronary artery account for only $18 \%$ of all coronary arterial (venous) fistulas [3]. More than 90\% of the fistulas drain into the right side of the heart with the most common sites of drainage being the right ventricle, right atrium, and pulmonary artery [4, 5]. Rarely, they drain into the CS in $7 \%$ and the superior vena cava in $1 \%$ of cases [4]. A fistula originating from the circumflex artery that drains into the coronary sinus is rare. In one literature review a total of 14 cases of LCX to CS fistula were reported [6]. Most of these cases were found incidentally in male and most common presentation was either dysnpnea on exertion or chest pain, rarely can remain asymptomatic. Two cases involved inferior and inferolateral myocardial infarction related to the CAF with patent epicardial coronary arteries [6]. The dilation of the coronary artery may relate to prolonged hyperdynamic circulation from the fistula.

Our patient presented in his late fifties. He was healthy with no limitation in physical activity. His initial presentation was one of an acute coronary syndrome which was confirmed by his electrocardiography and troponin abnormalities. His symptoms were likely secondary to significant shunt-induced ischemia triggered by increased physical activity during skiing. The diagnosis of the fistula in our patient was established by invasive coronary angiography and CT coronary angiography.

The management of coronary arteriovenous fistulas remains controversial. There are significant differences in the clinical presentation, size and anatomical connection of coronary artery fistulas, which has led to a lack of consistent guidelines for treatment [7]. In the most recent American College of Cardiology/American Heart Association Guidelines for the Management of

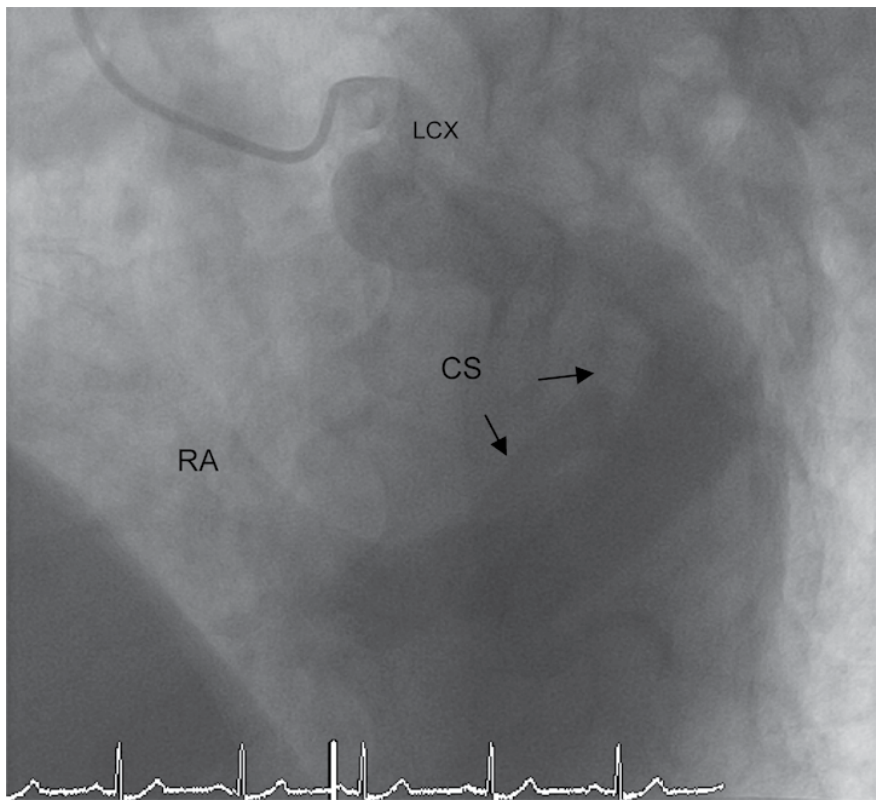

Figure 1: Coronary angiogram showing: dilated LCX artery and the fistula to the CS. RA (right atrium).
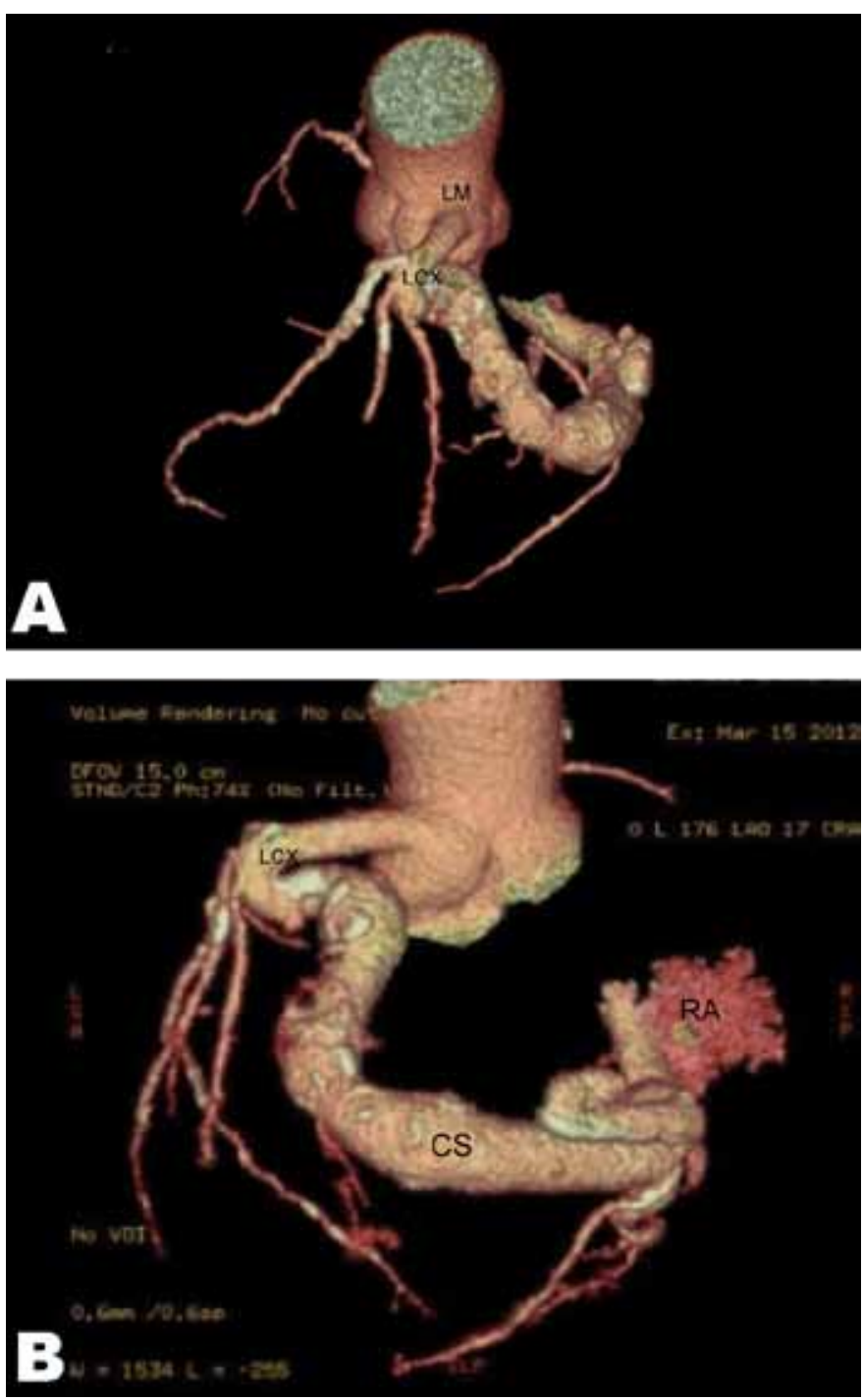

Figure 2: (A, B) Three-dimensional computed tomography image showing the ectatic LCX, fistula to the CS and the blood blush to the RA. LM (left main artery). 
Adults with Congenital Heart Disease [8], percutaneous or surgical closure is a Class I recommendation for large fistulae regardless of symptoms and for smallto moderate-size fistulae with evidence of myocardial ischemia, arrhythmia, ventricular dysfunction, ventricular enlargement or endarteritis. The optimal treatment modality for a patient depends on their age, the morphology and size of the fistula and the presence or absence of associated heart disease. Our patient was a candidate for surgical intervention due to the presence of symptoms of ischemic heart disease because he had a large, tortuous aneurysm. As in the previously reported cases, the fistula in our case was successfully ligated at the origin and at the site of termination into the CS.

\section{CONCLUSION}

Coronary artery fistulas are uncommon and can have different presentations ranging from asymptomatic to acute coronary syndromes. The management of coronary artery fistulae depends on the severity and the clinical presentation of these congenital anomalies.

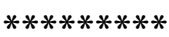

\section{Author Contributions}

Ahmed Sayed - Substantial contributions to conception and design, Acquisition of data, Analysis and interpretation of data, Drafting the article, Revising it critically for important intellectual content, Final approval of the version to be published

\section{Guarantor}

The corresponding author is the guarantor of submission.

\section{Conflict of Interest}

Authors declare no conflict of interest.

\section{Copyright}

(C) Ahmed Sayed 2013; This article is distributed under the terms of Creative Commons attribution 3.0 License which permits unrestricted use, distribution and reproduction in any means provided the original authors and original publisher are properly credited. (Please see www.ijcasereportsandimages.com/copyright-policy.php for more information.)

\section{ACKNOWLEDGEMENTS}

I would like to thank Dr. Wardal for the time and effort that he spent in the critical revision of this article.

\section{REFERENCES}

1. Ogden JA. Congenital anomalies of the coronary arteries. Am J Cardiol 1970 Apr;25(4):474-9.

2. Angelini P, Villason S, Chan AV Jr, et al. Normal and anomalous coronary arteries in humans. In Angelini P (ed): Coronary Artery Anomalies: A Comprehensive Approach. Lippincott Williams \& Wilkins, Baltimore, 1999, pp. 27-79.

3. Fernandes ED, Kadivar H, Hallman GL, Reul GJ, Ott DA, Cooley DA. Congenital malformations of the coronary arteries: The texas heart institute experience. Ann Thorac Surg 1992 Oct;54(4):732-40.

4. Dodge-Khatami A, Mavroudis C, Backer CL. Congenital heart surgery nomenclature and database project: Anomalies of the coronary arteries. Ann Thorac Surg 2000 Apr;69(4 Suppl):S270-97.

5. Darwazah AK, Hussein IH, Hawari MH. Congenital circumflex coronary arteriovenous fistula with aneurysmal termination in the pulmonary artery. Tex Heart Inst J 2005;32(1):56-9.

6. Said SA, van der Sluis A, Koster K, Sie H, Shahin GM. Congenital circumflex artery-coronary sinus fistula in an adult female associated with severe mitral regurgitation and myelodysplasy--case report and review of the literature. Congenit Heart Dis 2010 Nov-Dec;5(6):599-606.

7. Angelini P. Coronary fistulae. Which ones deserve treatment, and what kind of treatment do they need? Tex Heart Inst J 2007;34(2):202-3.

8. Warnes CA, Williams RG, Bashore TM, et al. ACC/ AHA 2008 guidelines for the management of adults with congenital heart disease: a report of the American College of Cardiology/American Heart Association Task Force on Practice Guidelines (Writing Committee to Develop Guidelines on the Management of Adults With Congenital Heart Disease). Developed in Collaboration With the American Society of Echocardiography, Heart Rhythm Society, International Society for Adult Congenital Heart Disease, Society for Cardiovascular Angiography and Interventions, and Society of Thoracic Surgeons. J Am Coll Cardiol 2008 Dec 2;52(23):e143-263. 
Access full text article on other devices

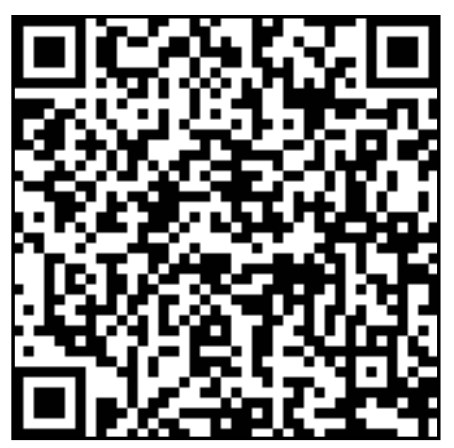

Access PDF of article on other devices

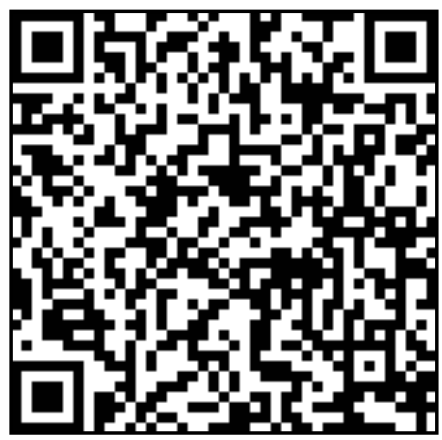

